\title{
An open-label trial of rituximab therapy in pulmonary alveolar proteinosis
}

\author{
M.S. Kavuru*, A. Malur*, I. Marshall*, B.P. Barna*, M. Meziane* , I. Huizar*, \\ H. Dalrymple*, R. Karnekar* and M.J. Thomassen*
}

ABSTRACT: Rituximab, a monoclonal antibody directed against the B-lymphocyte antigen CD20, has shown promise in several autoimmune disorders. Pulmonary alveolar proteinosis (PAP) is an autoimmune disorder characterised by autoantibodies to granulocyte-macrophage colonystimulating factor (GM-CSF).

An open-label, proof-of-concept phase II clinical trial was conducted in 10 PAP patients. The intervention consisted of two intravenous infusions of rituximab $(1,000 \mathrm{mg}) 15$ days apart. Bronchoalveolar lavage (BAL) fluid and peripheral blood samples were collected.

The primary outcome was improvement in arterial blood oxygenation. Both arterial oxygen tension and alveolar-arterial oxygen tension difference in room air improved in seven out of the nine patients completing the study. Lung function and high-resolution computed tomography scans, which were secondary outcomes, also improved. Peripheral blood CD19+ B-lymphocytes decreased from mean \pm SEM $15 \pm 2 \%$ to $<0.05 \%(n=10) 15$ days post-therapy. This decrease persisted for 3 months in all patients; at 6 months, CD19+ B-cells were detected in four out of seven patients $(5 \pm 2 \%)$. Total anti-GM-CSF immunoglobulin (Ig)G levels from baseline to 6 months were decreased in BAL fluids $(n=8)$ but unchanged in sera $(n=9)$.

In this PAP cohort: 1) rituximab was well-tolerated and effectively ameliorated lung disease; and 2) reduction in anti-GM-CSF IgG levels in the lung correlated with disease changes, suggesting that disease pathogenesis is related to autoantibody levels in the target organ.

KEYWORDS: B-cells, bronchoalveolar lavage, pulmonary alveolar proteinosis, rituximab

R ituximab, a chimeric murine-human monoclonal antibody directed against CD20, a B-lymphocyte-specific membrane antigen, has been shown to deplete human B-cells in vivo [1]. B-lymphocyte depletion in peripheralblood occurs rapidly, within days after rituximab administration. Proposed mechanisms of B-cell depletion by rituximab include complement-mediated cytotoxicity, antibody-dependent cell-mediated cytotoxicity and antibody-mediated apoptosis [2].

Rituximab was approved by the US Food and Drug Administration (FDA) in 1997 for treatment of CD20+ B-cell lymphoma and has since been in use for B-cell malignancies. More recently, rituximab has been applied to the treatment of autoimmune disease, and has shown clinical benefit in systemic lupus erythematosus [2], rheumatoid arthritis [3] and granulomatosis with polyangiitis (Wegener's) [4], among others. Rituximab treatment has been found to reduce autoantibody levels to a greater extent than it reduces levels of total serum immunoglobulin (Ig) or antimicrobial antibodies [5]. It is important to note that rituximab was added to other immunosuppressive therapies in these studies, making it difficult to assess the direct effect of rituximab on human autoimmunity. CD20, the target of rituximab binding, is a $35-\mathrm{kDa}$ cell membrane protein considered to play a role in B-cell cycling and differentiation [6]. CD20 first appears in the early pre-B-cell stage and expression diminishes with terminal differentiation into plasma cells; thus, CD20 is detectable on most precursor B-cells within the bone marrow, and on immature, mature-naïve and memory B-cells [2].

Pulmonary alveolar proteinosis (PAP) is a rare idiopathic disease noted for deposition of extracellular lipoproteinaceous material within pulmonary alveoli. With the discovery that genetically altered mice homozygous for a disrupted granulocytemacrophage colony-stimulating factor (GM-CSF) gene developed excess lung surfactant and had a histological resemblance to PAP $[7,8]$, the pivotal

\section{AFFILIATIONS}

*Program in Lung Cell Biology and Translational Research, Division of Pulmonary, Critical Care and Sleep Medicine, East Carolina University, Greenville, NC, and

${ }^{\#}$ Imaging Institute, Cleveland Clinic Foundation, Cleveland, $\mathrm{OH}$, USA.

\section{CORRESPONDENCE}

M.J. Thomassen

Division of Pulmonary, Critical Care and Sleep Medicine, East Carolina University

Brody School of Medicine

3E-149 Brody Medical Sciences

Building

Greenville

NC 27834

USA

E-mail: thomassenm@ecu.edu

Received:

Dec 212010

Accepted after revision:

March 162011

First published online:

April 082011 
role of GM-CSF in normal lung homeostasis was revealed. Interestingly, in adults with PAP, no mutations in GM-CSF receptor or surfactant coding sequences have been described [9]. Studies of GM-CSF knockout mice initially suggested that PAP might be due to intrinsic defects in GM-CSF receptors or production. However, studies from our lab and others demonstrated that monocytes and alveolar macrophages from adult PAP patients were able to produce and respond to GM-CSF [10, 11]. Evidence that adult PAP might be an autoimmune disease was first presented by KITAMURA et al. [12] and TANAKA et al. [13], who noted that circulating anti-GM-CSF autoantibodies neutralised GM-CSF biological activity, thus resulting in a virtual GMCSF deficiency. Subsequent studies in idiopathic adult PAP patients confirmed the existence of anti-GM-CSF antibodies and demonstrated that autoantibody levels were clinically useful for diagnosis [14-17].

Thus, based upon current data indicating autoantibody involvement in PAP, we hypothesised that reduction of PAP B-cells in the context of a rituximab clinical trial would diminish levels of anti-GM-CSF autoantibodies. Furthermore, we hypothesised that decreasing autoantibody levels would allow restoration of surfactant catabolism and resolution of clinical disease.

\section{METHODS}

\section{Study design}

This study was a prospective, open-label, proof-of-concept clinical trial of rituximab therapy in a group of 10 adult patients presenting with moderately symptomatic, idiopathic PAP. The study was approved by the Institutional Review Board at East Carolina University (Greenville, NC, USA) and informed consent was obtained from all patients. The trial was registered at ClinicalTrials.gov (NCT00552461). The diagnosis of idiopathic PAP was confirmed by open-lung biopsy $(n=3)$ or bronchoscopy $(n=7)$. All patients had moderately severe PAP and elevated anti-GM-CSF levels in sera (table 1). A total of five visits were scheduled in which rituximab $(1,000 \mathrm{mg})$ was administered intravenously as an infusion during visits 1 and 2 (see online supplementary material for monitoring during therapy and follow-up). Bronchoscopy was performed before the initial infusion and at 6 months after treatment. Serum samples were collected before infusions 1 and 2, and at each subsequent visit (fig. 1).

\section{Study eligibility}

Eligibility criteria included the following: 1) newly diagnosed PAP or chronic, long-standing disease in patients aged $>18$ yrs; 2) moderately symptomatic disease, as defined by the presence of symptoms attributable to PAP (e.g. dyspnoea and cough), moderately impaired gas exchange (arterial oxygen tension $\left(\mathrm{Pa}_{\mathrm{a}} \mathrm{O}_{2}\right)<70$ and $>55 \mathrm{mmHg}$ on room air or supplemental $\mathrm{O}_{2} \leqslant 6 \mathrm{~L} \cdot \mathrm{min}^{-1}$ via nasal cannula), and radiographic abnormalities; and 3) presence of high-titre anti-GMCSF antibody ( $\geqslant 6,400$ dilution). Exclusion criteria included the following: 1) PAP resulting from another condition (e.g. occupational exposure to silica, underlying HIV, respiratory infections, myeloproliferative disorder or leukaemia); 2) active cardiovascular disease (e.g. cardiogenic pulmonary oedema); 3) pregnancy or lactation in females; and 4) renal (serum

\begin{tabular}{|c|c|c|}
\hline TABLE 1 & \multicolumn{2}{|c|}{$\begin{array}{l}\text { Patient demographics and clinical } \\
\text { characteristics }\end{array}$} \\
\hline \multicolumn{2}{|l|}{ Subjects } & 10 \\
\hline \multicolumn{2}{|l|}{ Age yrs } & $41(22-68)$ \\
\hline \multicolumn{2}{|c|}{ Males/females } & $7 / 3$ \\
\hline \multicolumn{2}{|c|}{ Caucasians/African Americans } & $8 / 2$ \\
\hline \multicolumn{2}{|c|}{ Current smokers/nonsmokers/ex-smokers } & $3 / 3 / 4$ \\
\hline \multicolumn{2}{|c|}{ Duration of PAP months } & $15(2-115)$ \\
\hline \multicolumn{2}{|c|}{ Serum anti-GM-CSF $\mu \mathrm{g} \cdot \mathrm{mL}^{-1}$} & $1227 \pm 343$ \\
\hline \multicolumn{2}{|c|}{ Baseline home $\mathrm{O}_{2}$} & $8 / 10$ \\
\hline \multicolumn{2}{|l|}{ Prior WLLs } & $5.1(0-16)$ \\
\hline \multicolumn{2}{|c|}{ Time since last WLL months } & $5.8(1-29)$ \\
\hline \multicolumn{2}{|c|}{ Functional dyspnoea grade Mahler's BDI" } & $1.0(0-2.5)$ \\
\hline \multicolumn{3}{|c|}{$\begin{array}{l}\text { Data are presented as } n \text {, median (range) or mean } \pm \text { SEM. PAP: pulmonary } \\
\text { alveolar proteinosis; GM-CSF: granulocyte-macrophage colony-stimulating } \\
\text { factor; WLL: whole-lung lavage; BDI: baseline dyspnoea index. }{ }^{*} \text { : scale 0-4. }\end{array}$} \\
\hline
\end{tabular}

creatinine more than twice the normal level) or liver (bilirubin more than twice or enzymes $>2.5$ times normal) disease.

\section{Assessments}

The primary study end-point was an improvement in oxygenation, as assessed by the alveolar-arterial oxygen tension difference $\left(P \mathrm{~A}-\mathrm{a}, \mathrm{O}_{2}\right)$. A reduction in $\mathrm{PA}-\mathrm{a}, \mathrm{O}_{2}$ of $10 \mathrm{mmHg}$ was considered significant. Other end-points included: 1) improvement in patients' symptoms, as assessed by functional status with Mahler's dyspnoea questionnaire [18], forced expiratory volume in $1 \mathrm{~s}$, diffusing capacity of the lung for carbon monoxide (DL,CO), 6-min walk distance/oxygen saturation and chest computed tomography (CT) severity index; 2) overall tolerability of therapy; 3) requirement for whole-lung lavage (WLL); 4) sustainability of response, assessed by follow-up telephone interviews; and 5) change in serum anti-GM-CSF level, and markers for B- and T-cells.

\section{Radiographic grading}

De-identified chest high-resolution CT (HRCT) scans obtained prior to therapy and 6 months post-therapy were evaluated by a board-certified radiologist $[19,20]$. Briefly, the extent of groundglass opacity (GGO) was quantified visually in CT slices representing the three lung regions: upper (above the aortic arch), middle (at the main carina) and lower (at the bifurcation of the linear and lower-lobe bronchi). Scans were scored as 0 (no GGO), 1 (<5\% GGO), 2 (5-24\% GGO), 3 (25-49\% GGO), 4 (50-74\% GGO)

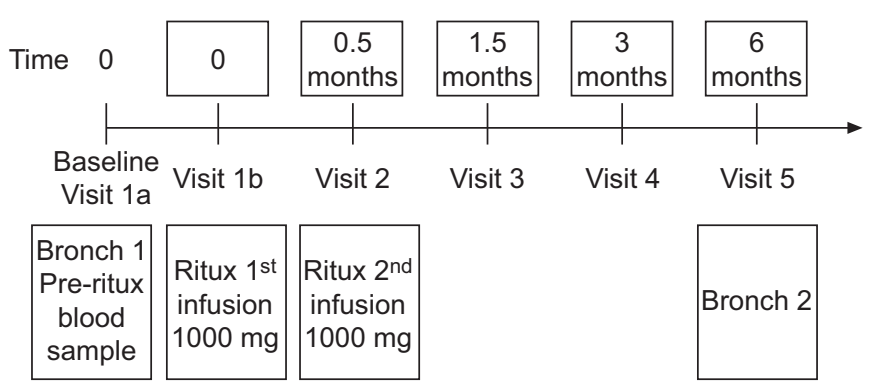

FIGURE 1. Schematic of study visits for rituximab trial. Bronch: bronchoscopy; ritux: rituximab. 
or $5(\geqslant 75 \%$ GGO). The total score was calculated as the sum of all HRCT scores for each scan.

\section{Laboratory measurements}

Bronchoalveolar lavage (BAL) was carried out prior to and 6 months after therapy, as described previously [10, 21]. For autoantibody analyses of both BAL fluids and sera, anti-GMCSF IgG levels were determined using the Luminex technology [22], and GM-CSF-neutralising activity was evaluated by bioassay of TF-1 cells, as previously described [10]. Peripheral blood white blood cells, haemoglobin, platelets, total Ig and IgG subclasses were all quantified by standard methods. Flow cytometry was used to quantify peripheral blood B-cells using CD19, and CD4 and CD8 for T-cells.

\section{Statistical analysis}

Parametric data are presented as mean \pm SEM and nonparametric data are presented as median (range). Statistical comparisons of parametric data were made using paired t-tests. Nonparametric data were compared with the Wilcoxon test. The correlation coefficient was obtained using Spearman's correlation. $p \leqslant 0.05$ was considered significant.

\section{RESULTS}

\section{Patients}

10 patients were enrolled in the study and received rituximab infusions. One patient dropped out of the study after the second infusion for unknown reasons. The remaining nine patients completed the 6-month study period. Table 2 summarises the clinical parameters pre- and post-rituximab.

\section{Safety of rituximab}

No major pulmonary or cardiac infusion-related reactions were noted. The majority of adverse events in 10 patients were minor (table 3) with most occurring at the time of the rituximab infusions. Two patients reported an upper respiratory tract infection. No other infections were documented.

\section{Primary outcome}

Combined data from all patients indicated that oxygenation, the primary end-point, significantly improved over baseline values. $\mathrm{Pa}_{1} \mathrm{O}_{2}$ was significantly improved from median 57 (range 4567) $\mathrm{mmHg}$ at baseline to $69(46-102) \mathrm{mmHg}$ at 3 months $(\mathrm{p}=0.008 ; \mathrm{n}=9)$ and $74(46-95) \mathrm{mmHg}$ at 6 months $(\mathrm{p}=0.004$; $\mathrm{n}=9$ ) (fig. 2a), while $\mathrm{PA}-\mathrm{a}, \mathrm{O}_{2}$ improved from 49 (38-61) $\mathrm{mmHg}$ at baseline to $33(5-39) \mathrm{mmHg}$ at 3 months $(p=0.010)$ and 33 $(5-49) \mathrm{mmHg}$ at 6 months $(\mathrm{p}=0.006)$ (fig. $2 b)$.

\section{Additional pulmonary outcomes}

Absolute and \% predicted total lung capacity (TLC) showed significant improvement overall (table 2) but other lung function parameters (absolute and \% pred forced vital capacity and $D \mathrm{~L}, \mathrm{CO})$ were unchanged from baseline. Assessment of functional status indicated improvement in both magnitude of effort and magnitude of task grades (table 2), but not in functional impairment grade or the 6-min walk test. Chest HRCT scans improved after rituximab therapy $(\mathrm{p}=0.027)$ (fig. $2 \mathrm{c})$. Marked improvement in ground-glass infiltrates post-therapy was noted in a representative mid zone of patient 8 as compared with the pre-therapy scan (fig. $2 \mathrm{~d}$ and e). Furthermore, HRCT scores correlated with $\mathrm{Pa}_{\mathrm{a}} \mathrm{O}_{2}\left(\mathrm{r}^{2}=-0.696, \mathrm{p}=0.0019\right)$.

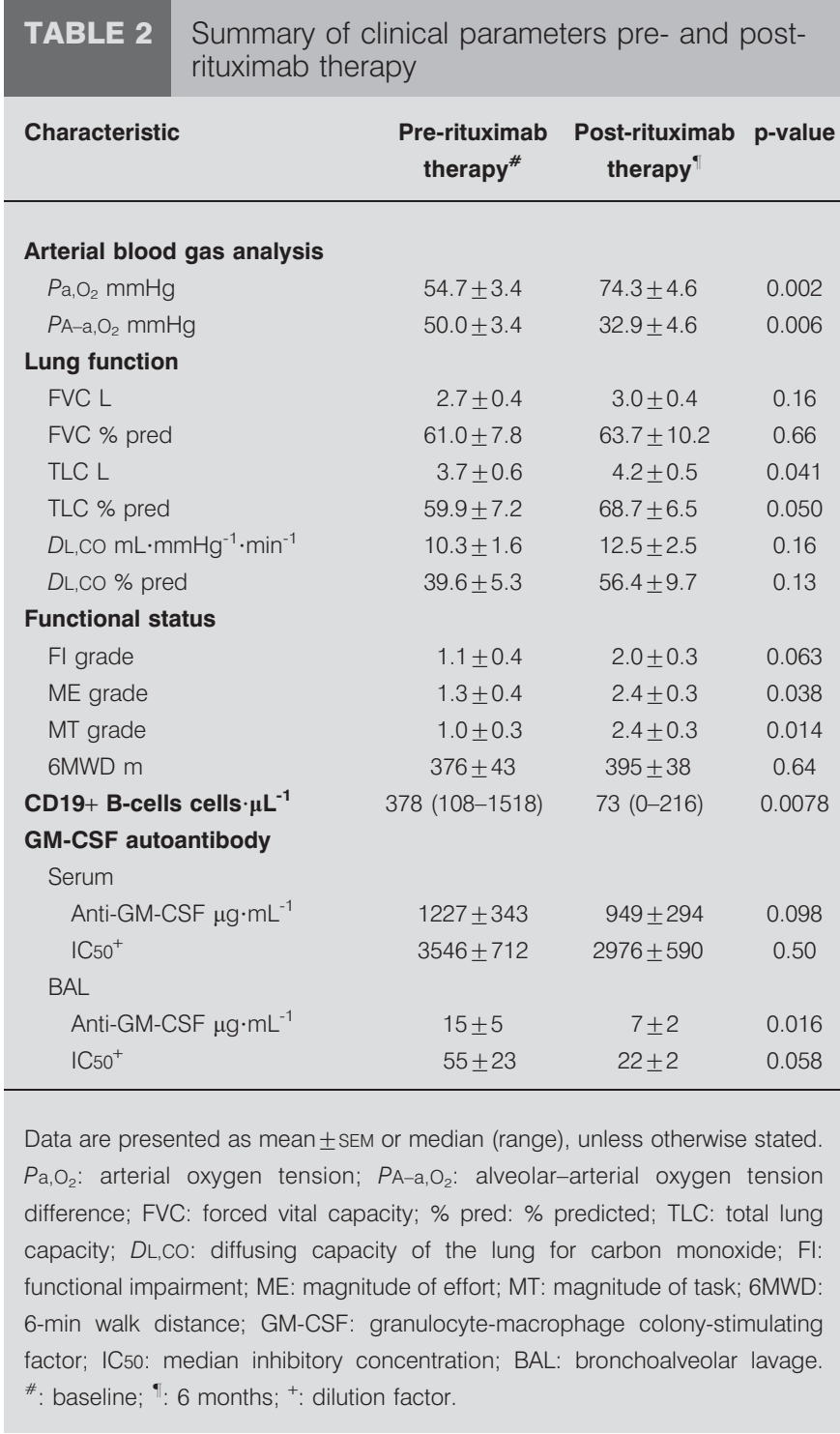

\section{Peripheral blood studies}

Total white blood cell counts did not change from baseline or at any time-point during follow-up, nor did absolute numbers of neutrophils, eosinophils, platelets or haemoglobin (table 2). Absolute numbers of monocytes showed a slight but significant decrease.

Flow cytometry indicated a dramatic depletion of CD19+ B-cells from $378(108-1,518)$ cells $\cdot \mu \mathrm{L}^{-1}$ at baseline to $73(0-216)$ cells $\cdot \mu \mathrm{L}^{-1}$ after rituximab infusions $(p=0.008 ; n=10)$ (fig. 3 ). This depletion was maintained for 3 months. Increases in CD19+ cells were not detectable until 6 months (four out of seven patients). No significant changes in CD4+ or CD8+ T-cells were observed (online supplementary table 1).

\section{Immunoglobulins and autoantibodies}

Total levels of serum IgG, IgG1, IgG2, IgG3 and IgG4 were unchanged (table 2 and online supplementary table 1). Serum IgA was also unchanged, but significant decreases were noted in total $\operatorname{IgM}(\mathrm{p}=0.004)$ and $\operatorname{IgE}(\mathrm{p}=0.039)$ (table 2 and online supplementary table 1). 


\begin{tabular}{|c|c|}
\hline TABLE 3 Adverse el & \\
\hline Event & Subjects $n / N$ \\
\hline \multicolumn{2}{|l|}{ General } \\
\hline Fatigue & $5 / 10$ \\
\hline Headache & $4 / 10$ \\
\hline Dizziness & $3 / 10$ \\
\hline \multicolumn{2}{|l|}{ Digestive } \\
\hline Nausea & $3 / 10$ \\
\hline Anorexia & $2 / 10$ \\
\hline Weight gain & $3 / 10$ \\
\hline Skin reactions & $1 / 10$ \\
\hline \multicolumn{2}{|l|}{ Respiratory system } \\
\hline Nasal congestion & $5 / 10$ \\
\hline Upper respiratory infection & $2 / 10$ \\
\hline Chest pains & $1 / 10$ \\
\hline
\end{tabular}

Overall, rituximab therapy did not significantly alter mean serum levels of specific anti-GM-CSF neutralising activity (median inhibitory concentration (IC50) 3,903 (956-6,826) at baseline and 2,950 (747-5,692) 6 months post-treatments) $(\mathrm{n}=9)$ (fig. 4a). Similarly, anti-GM-CSF IgG autoantibody $\left(1,086(150-3,532) \mu \mathrm{g} \cdot \mathrm{mL}^{-1}\right.$ at baseline) was also not significantly changed in serum post-treatment $\left(726(139-3,028) \mu \mathrm{g} \cdot \mathrm{mL}^{-1}\right)$ (fig. $4 \mathrm{~b})$. Analysis of BAL fluid $(n=8)$ indicated a significant decrease in BAL fluid anti-GM-CSF IgG levels (8.2 (3.941.2) $\mu \mathrm{g} \cdot \mathrm{mL}^{-1}$ at baseline) 6 months post-treatment (6.1 (0.314.7) $\left.\mu \mathrm{g} \cdot \mathrm{mL}^{-1}\right) \quad(\mathrm{p}=0.016)$ (fig. $\left.4 \mathrm{~d}\right)$. A borderline reduction of BAL anti-GM-CSF neutralising activity was detected (IC50 30.5 (15-210) at baseline and 22.5 (5-50) 6 months post-treatment; $\mathrm{p}=0.058$ ) (fig. 4c). Notably, only patient 1 had an increase in neutralising antibody in BAL and two patients (patients 3 and 7) showed no change. The remaining five patients demonstrated marked decreases in BAL autoantibody (33-87\%), including patient 4 , whose $\mathrm{Pa}_{1} \mathrm{O}_{2}$ was unchanged but whose HRCT scan showed improvement. Therapy-associated changes in both BAL total anti-GM-CSF IgG and neutralising anti-GM-CSF correlated with HRCT scores $\left(\mathrm{r}^{2}=0.929, \mathrm{p}=0.007\right.$ and $\mathrm{r}^{2}=0.991, \mathrm{p}=0.0004$, respectively). Anti-GM-CSF IgM and IgE were not detected at baseline or 6 months post-treatment.

Interestingly, analyses of the BAL cell population revealed no significant changes in cell number or differential between baseline and 6 months post-treatment (data not shown). CD19+ cells (2-3\%) were detected in BAL by flow cytometry in two out of seven patients at baseline and none were detected at 6 months.
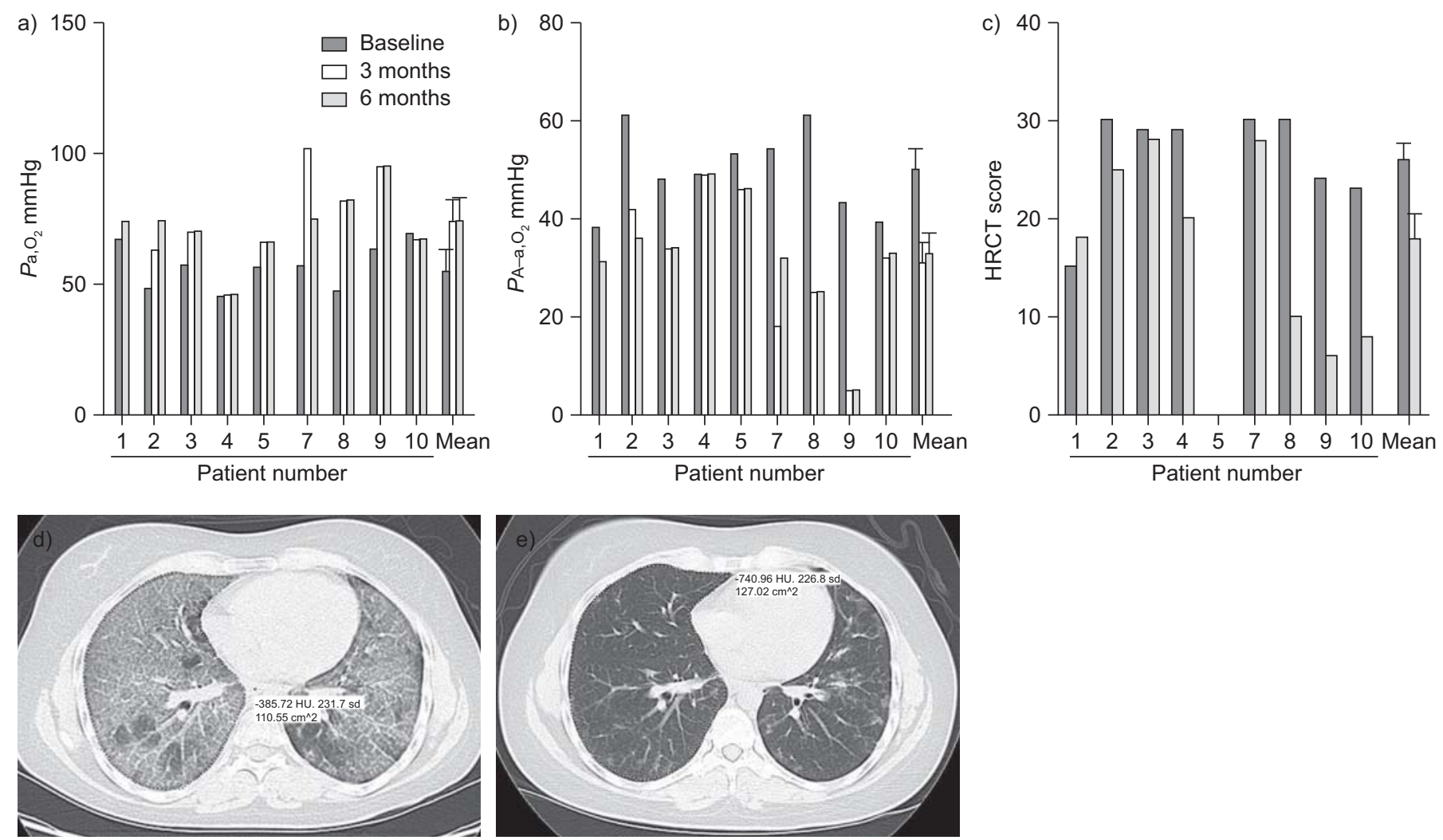

FIGURE 2. Lung function parameters are improved with rituximab treatment. a) Arterial oxygen tension $\left(\mathrm{Pa}, \mathrm{O}_{2}\right)$ and b) alveolar-arterial oxygen tension difference $\left(P \mathrm{~A}-\mathrm{a}, \mathrm{O}_{2}\right)$ were measured at baseline (before rituximab), and 3 and 6 months post-treatment in all patients except patient 1, where a 3-month sample was not obtained, and patient 6 , who refused clinical follow-up after visit 3. c) High-resolution computed tomography (HRCT) demonstrated improvement with rituximab therapy. The effect of rituximab therapy on the severity of pulmonary alveolar proteinosis lung disease was measured by the zonal HRCT score [19], as described in the online supplementary material. Error bars represent the standard error of the mean. HRCT scan of a representative mid zone of patient 8: d) pre- and e) post-rituximab therapy. HU: Hounsfield unit. 


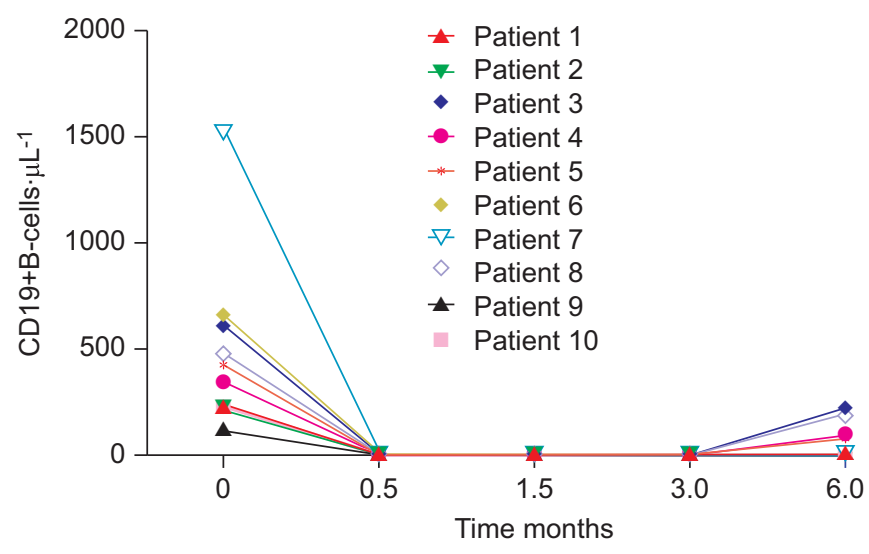

FIGURE 3. Rituximab therapy depletes B-cells. CD19+ cells were determined by flow cytometric analysis of blood samples at each study visit.

\section{Follow-up}

Post-therapy follow-up was obtained in seven out of 10 patients (table 4 ). The follow-up (mean \pm SEM $32 \pm 6$ months) showed four out of the seven patients to be free of WLL or home $\mathrm{O}_{2}$. Need for home $\mathrm{O}_{2}$ persisted in one patient (who was living at high altitude) and two patients required one WLL. Interestingly, one of these patients requiring WLL had undergone monthly WLL for 32 months prior to therapy.
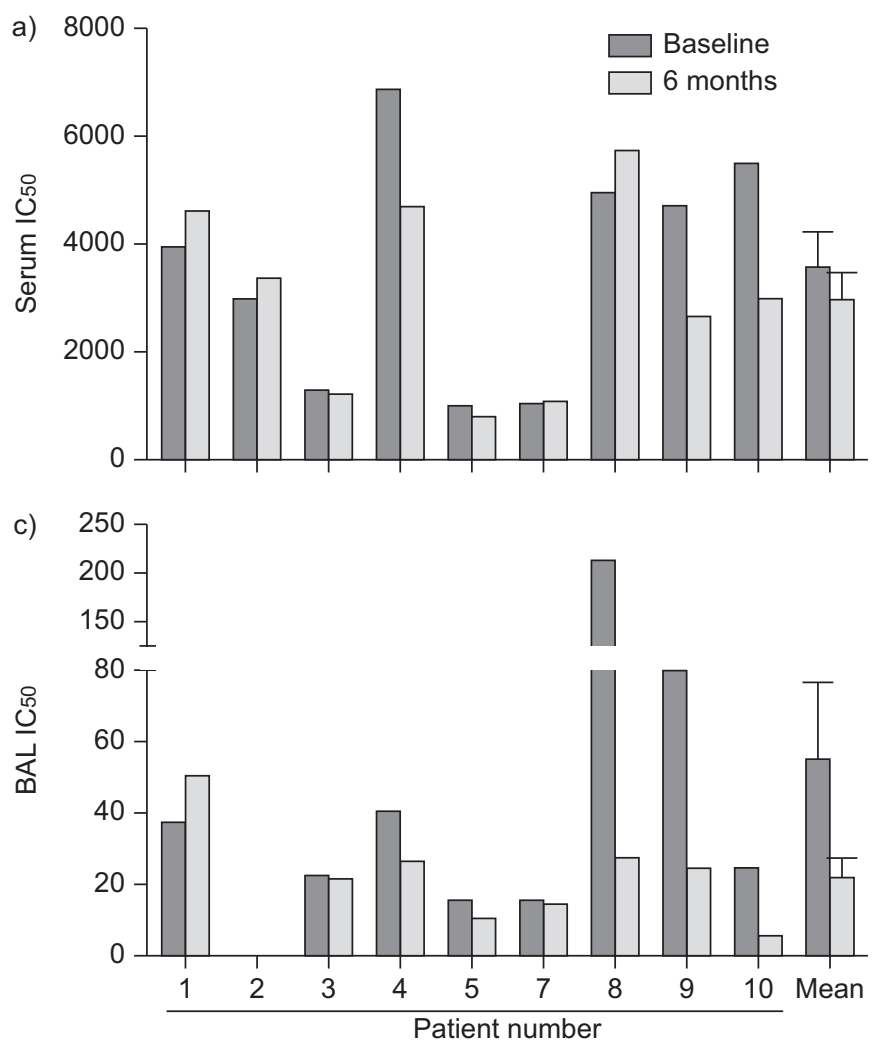

\section{DISCUSSION}

The present study reports the results from the first prospective, open-label, proof-of-concept trial of rituximab in PAP and suggests that rituximab may be an effective primary therapy in this autoimmune disease. The most striking clinical finding from this study of rituximab in PAP was the significant improvement of oxygenation, the primary end-point, in seven out of nine patients. Improvements were also noted in TLC, HRCT scans and a transitional dyspnoea index. Importantly, neither the total serum anti-GM-CSF nor the serum GM-CSF neutralising capacity were reduced following rituximab therapy. Interestingly, anti-GM-CSF levels in BAL fluid from the lung correlated with improvement in $\mathrm{Pa}_{\mathrm{a}} \mathrm{O}_{2}$ and HRCT scans. The data also indicated that rituximab was well tolerated, with no major adverse reactions in this PAP cohort.

Therapeutic WLL is considered the current standard of care (reviewed by SEYMOUR and PRESNEILl [23]) for PAP but has many limitations because of its invasiveness, need for general anaesthesia and requirement for hospitalisation. A randomised trial, or even a formal prospective study, of WLL has not been conducted to measure magnitude or durability of response in PAP. Thus, the clinical impact on PAP is uncertain, although lavage is the first-line therapy offered by clinicians and reimbursed by insurance companies because of perceived benefit. Furthermore, WLL procedures vary widely among institutions and there is a lack of established response criteria. Several clinical
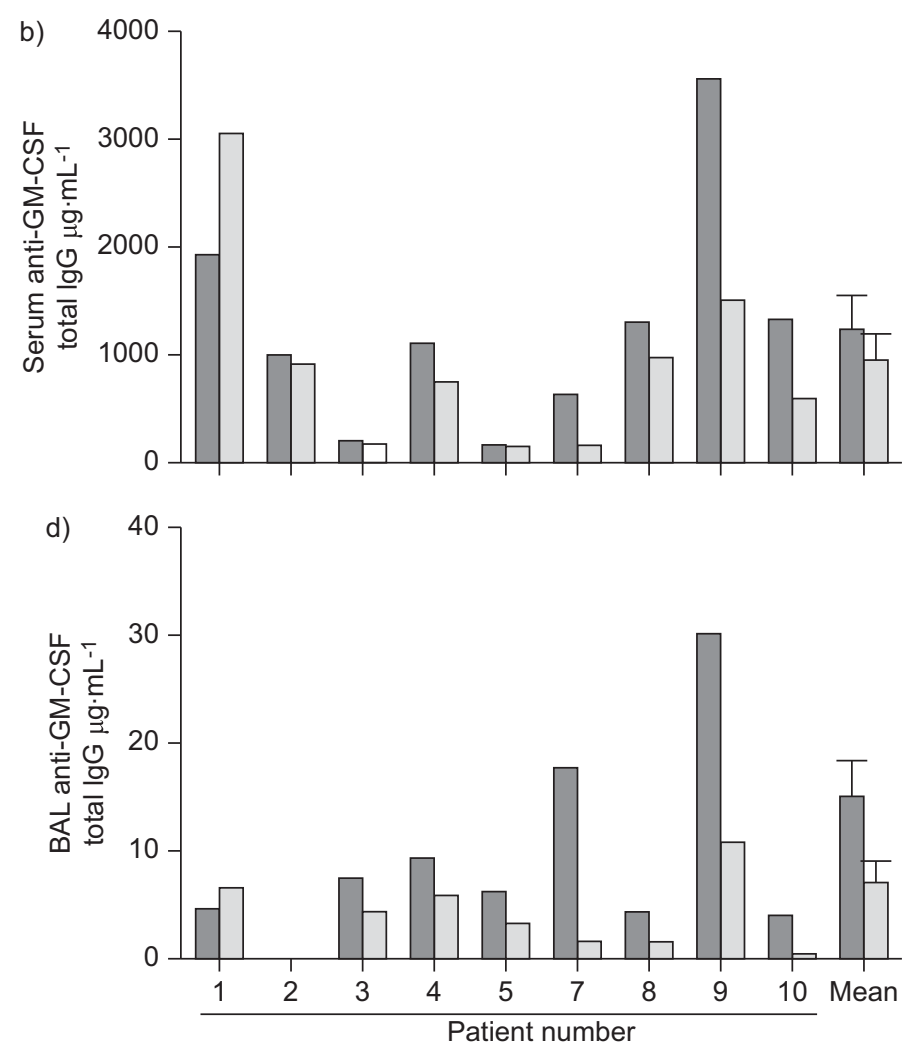

FIGURE 4. Serum a) granulocyte-macrophage colony-stimulating factor (GM-CSF) neutralising capacity and b) total anti-GM-CSF immunoglobulin (Ig)G were not altered with rituximab therapy. Serum samples were obtained pre- and post-rituximab therapy. GM-CSF neutralising activity was measured using the TF-1 assay, as described previously [10], and anti-GM-CSF antibody was determined by a Luminex-based assay, as described previously [22]. Bronchoalveolar lavage (BAL) fluid c) GM-CSF neutralising capacity and d) total anti-GM-CSF IgG were decreased with rituximab therapy. BAL fluid was obtained pre- and post-therapy, and antibody levels were measured as described for serum. Error bars represent standard error of the mean. IC50: median inhibitory concentration. 


\begin{tabular}{|c|c|c|c|c|}
\hline \multirow{2}{*}{$\begin{array}{l}\text { TABLE } 4 \\
\text { Patient }\end{array}$} & \multicolumn{4}{|c|}{ Patient follow-up } \\
\hline & $\begin{array}{c}\text { Time post- } \\
\text { therapy } \\
\text { months }\end{array}$ & $\begin{array}{c}\text { Hospitalisations } \\
n\end{array}$ & WLLs n & Home $\mathrm{O}_{2}$ \\
\hline 1 & 30 & 0 & 0 & $\mathrm{Yes}^{+}$ \\
\hline 2 & 42 & 0 & 0 & p.r.n. \\
\hline 3 & 36 & 0 & 0 & No \\
\hline \multicolumn{5}{|l|}{$4^{\#}$} \\
\hline \multicolumn{5}{|l|}{$5^{\#}$} \\
\hline $6^{\circ}$ & 36 & 0 & 0 & No \\
\hline 7 & 30 & 0 & 0 & No \\
\hline 8 & 25 & 1 & 1 & No \\
\hline 9 & 24 & 0 & 1 & No \\
\hline $10^{\#}$ & & & & \\
\hline
\end{tabular}

WLL: whole-lung lavage. ${ }^{\#}$ : lost to follow-up; ": patient refused clinical follow-up after third visit; ${ }^{+}$: patient was living at high altitude.

trials have used subcutaneous or inhaled GM-CSF on an experimental basis. We reported a prospective study of subcutaneous GM-CSF with a response rate of $48 \%$ and four out of 12 responders required additional therapy within mean \pm SD $39 \pm 17$ months [24]. Most recently, a multicentre phase II trial of inhaled GM-CSF therapy for PAP had a response rate of $62 \%$ during a 6-month treatment period [20] with $17 \%$ of patients requiring additional therapy within 1 yr. Neither subcutaneous nor inhaled GM-CSF has been formally compared with conventional management (observation with episodic lung lavage) and neither is currently FDA approved for use in PAP.

The role of autoantibodies in autoimmune diseases has not been clearly defined and may differ depending on disease stage and/or severity [25]. In PAP, studies have suggested a possible correlation of serum neutralising anti-GM-CSF levels with disease activity [26]. Plasmapheresis has been used with mixed results, as reported in two separate case studies [27, 28]. One patient showed marked improvement with reduction in antibody titre [27], while the other patient achieved only a minor reduction in antibody and this was not reflected in clinical improvement [28]. In a case study of a rituximabtreated PAP patient, clinical improvement correlated with a decline in serum neutralising antibody [29]. The present study did not show a significant correlation with serum activity, but direct comparison of other anti-GM-CSF assays [30] with the Luminex assay used in the present study is not possible because of differences in standards. To eliminate assay-toassay variability, all samples from an individual were run in the same assay and data were evaluated for the change in antibody levels. In BAL fluid, however, total anti-GM-CSF was significantly decreased and the neutralising activity was near significance at $\mathrm{p}=0.058$. Both the neutralising activity and total anti-GM-CSF levels in BAL correlated with improvement in HRCT scans, suggesting that autoantibody levels in the target organ correlate with pathophysiology. Although the source of the antibody may be the circulation, B-cells are found in the lung [31] and our previous studies have noted a decrease in activin A, a negative regulator of B-cell proliferation and activity, in PAP BAL fluid [32]. Our results support the concept that the pathology of PAP is mediated by GM-CSF autoantibody, as suggested by results from passive transfer of a highly purified, PAP patient-derived, anti-GM-CSF preparation to primates [33, 34]. PAP anti-GM-CSF antibody reproduced the biochemical, cellular and histopathological features of PAP in treated primates $[33,34]$.

The mechanisms responsible for rituximab-mediated improvement in PAP disease activity are unclear. While rituximab effectively depleted circulating B-lymphocytes for a period of 3 months in all nine patients completing the study, total serum IgG levels were unaffected by treatment, as has been reported previously in rituximab-treated systemic lupus erythematosus patients [35]. There were decreases in total $\operatorname{IgM}$ and $\operatorname{IgE}$ but autoantibody studies did not discern any anti-GM-CSF activity in either class of Ig (data not shown), in contrast to IgG autoantibody. VALLERSKOG et al. [35] also noted decreased IgM and IgE, and speculated that both might be produced by shortlived plasmablasts in contrast to IgG, and therefore would be more susceptible to rituximab.

Analysis of rituximab effects in other autoimmune disease is confounded by coexistent use of immunosuppressive drugs. PAP, although a rare disease, serves as an outstanding model of human autoimmunity, and these patients are typically not on systemic immunomodulators (none of the 10 subjects was on other therapies). The potential role of B-cells in PAP, however, is not well defined. B-cells participate in antigen presentation and regulatory signalling to T-cells and provide regulatory cytokine signals to dendritic cells [36, 37]. The majority of antibodyforming B-cells are plasma cells, which do not express CD20 and are, therefore, not susceptible to rituximab depletion [25]. Animal models suggest that reductions in autoantibody levels may be due to removal of short-lived antibody-forming cells or depletion of plasmablast precursors [38]. Additional studies are needed to explore the mechanisms by which rituximab mediates clinical improvement in PAP.

In conclusion, a single course of rituximab therapy for PAP is safe, well tolerated and efficacious. Rituximab may constitute an appropriate therapeutic alternative to WLL, the current standard of therapy. Furthermore, reduction in anti-GM-CSF IgG levels in the lung correlated with disease changes, supporting the concept that disease pathogenesis is related to autoantibody levels in the target organ. Limitations of the present study include the open-label design and the absence of a placebo group. Questions remain concerning the durability of responses and the need for longer-term therapy. Nevertheless, given the pilot nature of the study, the rarity of the disease and a singlesite design, this trial achieved its objective of laying the foundation for a larger multicentre, randomised and controlled trial design of rituximab to establish frequency and duration of therapy for optimal treatment effects.

\section{SUPPORT STATEMENT}

This study was supported by Genentech (San Francisco, CA, USA) and by National Institutes of Health (Bethesda, MD, USA) grant RO1AI064153.

\section{CLINICAL TRIAL}

This study is registered at ClinicalTrials.gov with identifier number NCT00552461. 


\section{STATEMENT OF INTEREST}

A statement of interest for this study can be found at www.erj. ersjournals.com/site/misc/statements.xhtml

\section{REFERENCES}

1 Grillo-Lopez AJ, White CA, Varns C, et al. Overview of the clinical development of rituximab: first monoclonal antibody approved for the treatment of lymphoma. Semin Oncol 1999; 26: Suppl. 14, 66-73.

2 Anolik JI, Sanz, Looney RJ. B cell depletion therapy in systemic lupus erythematosus. Curr Rheumatol Rep 2003; 5: 350-356.

3 Edwards JC, Szczepanski L, Szechinski J, et al. Efficacy of B-celltargeted therapy with rituximab in patients with rheumatoid arthritis. N Engl J Med 2004; 350: 2572-2581.

4 Stone JH, Merkel PA, Spiera R, et al. Rituximab versus cyclophosphamide for ANCA-associated vasculitis. N Engl J Med 2010; 363: 221-232.

5 Cambridge G, Leandro MJ, Edwards JC, et al. Serologic changes following B lymphocyte depletion therapy for rheumatoid arthritis. Arthritis Rheum 2003; 48: 2146-2154.

6 Tedder TF, Engel P. CD20: a regulator of cell-cycle progression of B lymphocytes. Immunol Today 1994; 15: 450-454.

7 Dranoff G, Crawford AD, Sadelain M, et al. Involvement of granulocyte-macrophage colony-stimulating factor in pulmonary homeostasis. Science 1994; 264: 713-716.

8 Stanley E, Lieschke GJ, Grail D, et al. Granulocyte/macrophage colony-stimulating factor-deficient mice show no major perturbation of hematopoiesis but develop a characteristic pulmonary pathology. Proc Natl Acad Sci USA 1994; 91: 5592-5596.

9 Huizar I, Kavuru MS. Alveolar proteinosis syndrome: pathogenesis, diagnosis, and management. Curr Opin Pulm Med 2009; 15 491-498.

10 Thomassen MJ, Yi T, Raychaudhuri B, et al. Pulmonary alveolar proteinosis is a disease of decreased availability of GM-CSF rather than an intrinsic cellular defect. Clin Immunol 2000; 95: 85-92.

11 Carraway MS, Ghio AJ, Carter JD, et al. Detection of granulocytemacrophage colony-stimulating factor in patients with pulmonary alveolar proteinosis. Am J Respir Crit Care Med 2000; 161: 12941299.

12 Kitamura TN, Tanaka J, Watanabe K, et al. Idiopathic pulmonary alveolar proteinosis as an autoimmune disease with neutralizing antibody against granulocyte/macrophage colony-stimulating factor. J Exp Med 1999; 190: 875-880.

13 Tanaka NJ, Watanabe T, Kitamura $Y$, et al. Lungs of patients with idiopathic pulmonary alveolar proteinosis express a factor which neutralizes granulocyte-macrophage colony-stimulating factor. FEBS Lett 1999; 442: 246-250.

14 Bonfield TL, Kavuru MS, Thomassen MJ. Anti-GM-CSF titer predicts response to GM-CSF therapy in pulmonary alveolar proteinosis. Clin Immunol 2002; 105: 342-350.

15 Bonfield TL, Russell D, Burgess S, et al. Autoantibodies against granulocyte macrophage colony-stimulating factor are diagnostic for pulmonary alveolar proteinosis. Am J Respir Cell Mol Biol 2002; 27: 481-486.

16 Seymour JF, Doyle IR, Nakata K, et al. Relationship of anti-GMCSF antibody concentration, surfactant protein A and B levels, and serum LDH to pulmonary parameters and response to GM-CSF therapy in patients with idiopathic alveolar proteinosis. Thorax 2003; 58: 252-257.

17 Kitamura T, Uchida K, Tanaka N, et al. Serological diagnosis of idiopathic pulmonary alveolar proteinosis. Am J Respir Crit Care Med 2000; 162: 658-662.
18 Mahler DA, Waterman LA, Ward J, et al. Validity and responsiveness of the self-administered computerized versions of the baseline and transition dyspnoea indexes. Chest 2007; 132: 1283-1290.

19 Akira MG, Inoue S, Yamamoto, et al. Non-specific interstitial pneumonia: findings on sequential CT scans of nine patients. Thorax 2000; 55: 854-859.

20 Tazawa RB, Trapnell C, Inoue Y, et al. Inhaled granulocyte/ macrophage-colony stimulating factor as therapy for pulmonary alveolar proteinosis. Am J Respir Crit Care Med 2010; 181: 1345-1354.

21 Thomassen MJ, Buhrow LT, Connors MJ, et al. Nitric oxide inhibits inflammatory cytokine production by human alveolar macrophages. Am J Respir Cell Mol Biol 1997; 17: 279-283.

22 Bonfield TL, John N, Barna BP, et al. Multiplexed particle-based anti-granulocyte macrophage colony stimulating factor (GM-CSF) assay used as pulmonary diagnostic test. Clin Diagn Lab Immunol 2005; 12: 821-824.

23 Seymour JF, Presneill JJ. Pulmonary alveolar proteinosis (progress in the first 44 years). Am J Respir Crit Care Med 2002; 166: 215-235.

24 Venkateshiah SB, Yan TD, Bonfield TL, et al. An open-label trial of granulocyte macrophage colony stimulating factor therapy for moderate symptomatic pulmonary alveolar proteinosis. Chest 2006; 130: 227-237.

25 Sanz I. Indications of rituximab in autoimmune diseases. Drug Discov Today Ther Strateg 2009; 6: 13-19.

26 Uchida K, Nakata K, Suzuki T, et al. Granulocyte/macrophagecolony-stimulating factor autoantibodies and myeloid cell immune functions in healthy subjects. Blood 2009; 113: 2547-2556.

27 Kavuru MS, Bonfield TL, Thomassen MJ. Plasmapheresis, GM-CSF, and alveolar proteinosis. Am J Respir Crit Care Med 2003; 167: 1036

28 Luisetti M, Rodi G, Perotti C, et al. Plasmapheresis for treatment of pulmonary alveolar proteinosis. Eur Respir J 2009; 33: 1220-1222.

29 Borie R, Debray MP, Laine C, et al. Rituximab therapy in autoimmune pulmonary alveolar proteinosis. Eur Respir J 2009; 33: 1503-1506.

30 Inoue $\mathrm{Y}$, Trapnell BC, Tazawa $\mathrm{R}$, et al. Characteristics of a large cohort of patients with autoimmune pulmonary alveolar proteinosis in Japan. Am J Respir Crit Care Med 2008; 177: 752-762.

31 Zeimpekoglou $\mathrm{K}$. The role of B-lymphocytes in lung disease. Pneumon 2008; 21: 196-199.

32 Bonfield TL, Barna BP, John N, et al. Suppression of activin A in autoimmune lung disease associated with anti-GM-CSF. J Autoimmun 2006; 26: 37-41.

33 Sakagami T, Beck D, Uchida K, et al. Patient-derived granulocyte/ macrophage colony-stimulating factor autoantibodies reproduce pulmonary alveolar proteinosis in nonhuman primates. Am Respir Crit Care Med 2010; 182: 49-61.

34 Sakagami T, Uchida K, Suzuki T, et al. Human GM-CSF autoantibodies and reproduction of pulmonary alveolar proteinosis. N Engl J Med 2010; 361: 2679-2681.

35 Vallerskog T, Gunnarsson I, Widhe M, et al. Treatment with rituximab affects both the cellular and the humoral arm of the immune system in patients with SLE. Clin Immunol 2007; 122: 62-74.

36 Perosa F, Prete M, Racanelli V, et al. CD20-depleting therapy in autoimmune diseases: from basic research to the clinic. J Intern Med 2010; 267: 260-277.

37 Leandro MJ, de la Torre I. Translational mini-review series on $B$ cell-directed therapies: the pathogenic role of $B$ cells in autoantibody-associated autoimmune diseases - lessons from B cell-depletion therapy. Clin Exp Immunol 2009; 157: 191-197.

38 Ahuja A, Shupe J, Dunn R, et al. Depletion of B cells in murine lupus: efficacy and resistance. J Immunol 2007; 179: 3351-3361. 